\title{
Multiple Method Development and Validation for Simultaneous Estimation of Chlorzoxazone and Nimesulide in Bulk and Pharmaceutical Dosage Form
}

\author{
Swetha Yarramsetti, A. Elphine Prabahar, Rama Rao Nadendla \\ Department of Pharmaceutical Analysis, Chalapathi Institute of Pharmaceutical Sciences, \\ Lam, Guntur, Andhra Pradesh, India
}

\begin{abstract}
A simple, precise and accurate multiple analytical method has been developed for the simultaneous estimation of Chlorzoxazone and Nimesulide in bulk and tablet formulations by reversed-phase liquid chromatographic and UV-Visible spectrophotometric techniques. The chromatographic separation was achieved on C18 analytical column. A mixture of Methanol: $0.1 \%$ Ortho-phosphoric acid (75:25) was used as mobile phase, at a flow rate of $1 \mathrm{~mL} / \mathrm{min}$ and detection wavelength at $295 \mathrm{~nm}$. The retention time of Chlorzoxazone and Nimesulide was found to be 4.69 and 5.45 min respectively. The linear dynamic ranges for HPLC were from 2-10 $\mu \mathrm{g} / \mathrm{mL}$ and for simultaneous equation method, derivative spectroscopy, Q-ratio Absorbance method, Dual wavelength it was $10-30 \mu \mathrm{g} / \mathrm{mL}$ for both Chlorzoxazone and Nimesulide. The percentage recovery obtained for Chlorzoxazone and Nimesulide were 100.93 and $102.19 \%$ respectively for RP-HPLC, $9.7 \%$ and $100.1 \%$ for simultaneous equation method of CZ and NIM respectively, $99.97 \%$ and $99.78 \%$ for derivative spectroscopy of CZ and NIM respectively, $101.37 \%$ and $99.48 \%$ for Q-ratio Absorbance method of CZ and NIM respectively, $100.13 \%$ and $99.96 \%$ for dual wavelength method of CZ and NIM respectively. The validation of the proposed methods were carried out for linearity, accuracy, precision, limit of detection, limit of quantitation and robustness. The developed method can be used for routine quality control analysis of titled drugs in combination in tablet formulation.
\end{abstract}

Keywords: Chlorzoxazone, Nimesulide, RP-HPLC, Uv-spectroscopy, derivative spectroscopy, Q-ratio Absorbance, Dual wavelength

\section{INTRODUCTION}

Chlorzoxazone is a centrally acting central muscle relaxant with sedative properties. It is 5-chloro-2,3-dihydro-1,3benzoxazol-2-one, which act by inhibiting calcium and potassium influx which would lead to neuronal inhibition and muscle relaxation. Nimesulide is a relatively COX-2 selective, non-steroidal anti-inflammatory drug (NSAID) with analgesic andantipyretic properties. Chemically it is $\mathrm{N}-$ (4-nitro-2-phenoxyphenyl) methane sulphonamide.

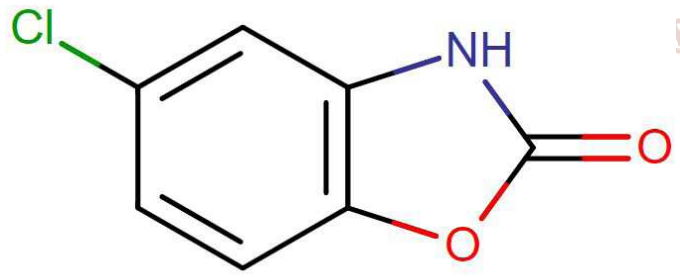

Figure: 1 Structure of Chlorzoxazone

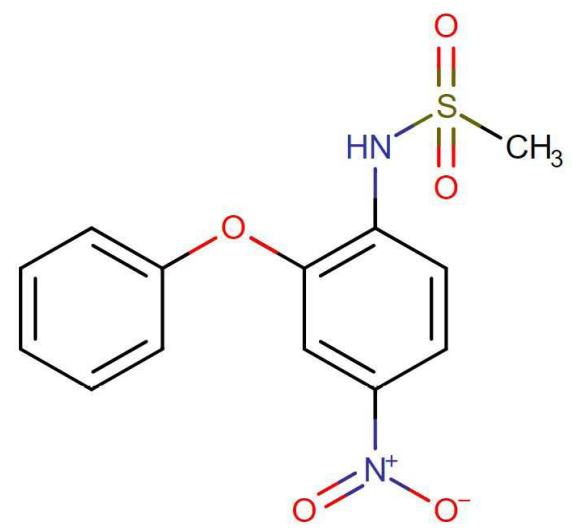

Figure: 2 Structure of Nimesulide
In this paper we have reported some of the analytical methods for the simultaneous determination of Chlorzoxazone and Nimesulide. Literature survey reveals only RP-HPLC and UV-spectroscopy for the simultaneous determination of the drugs in bulk or in the combined dosage forms and no spectroscopic methods such as Absorbance Ratio Method, Dual Wavelength Method and Derivative Spectroscopic Method. The method is described as new, simple, fast, rapid, accurate, efficient, reproducible for the development and validation analysis of simultaneous estimation of Chlorzoxazone and Nimesulide in pharmaceutical dosage form as per ICH guildelines.

\section{EXPERIMENTAL SECTION}

Chemicals and reagents used:

The reference standards of Chlorzoxazone and Nimesulide was procured from Aurbindo Pharma Limited, Hyderabad, India. Chemicals such as Acetonitrile, Methanol, Orthophosphoric acid and Dipotassium hydrogen Phosphate that were used for the chromatographic procedures are HPLC grade of Merck. Water for HPLC was used for the preparation of mobile phase. Pharmaceutical dosage form manufactured by Gracure Pharmaceutical Limited, (brand name- Nimox) by the composition of Nimesulide-100 $\mathrm{mg}$ and Chlorzoxazone$250 \mathrm{mg}$ was used for the study.

\section{Instrumentation:}

LABINDIA-UV 3092 UV/VIS spectrophotometer and HPLC system (AGILENT HPLC Model-1220 Infinity-LC with Ezchromelite Software) with gradient elution containing C 18 column with UV-detector were used. 


\section{Chromatographic conditions:}

The column used for chromatographic separations was $\mathrm{C} 18$ (4.6 i.d., $250 \mathrm{~mm}$ length, $5 \mu \mathrm{m}$ particle size). The analytical wavelength was set at $295 \mathrm{~nm}$ and samples of $20 \mu \mathrm{l}$ was injected manually. Chromatographic separations were performed by the mobile phase composition of Methanol : $0.1 \%$ Ortho-phosphoric acid (75:25) which is filtered through $0.22 \mu \mathrm{m}$ membrane filters and degassed in the ultrasonic bath. Mobile phase was injected through isocratic conditions with the flow rate of about $1 \mathrm{ml} / \mathrm{min}$.

\section{Preparation of standard and sample solutions:}

The standard solutions of Chlorzoxazone and Nimesulide was prepared by dissolving $10 \mathrm{mg}$ of drug in $3 \mathrm{ml}$ and $10 \mathrm{ml}$ of HPLC grade methanol respectively and the volume was made upto $10 \mathrm{ml}$ with HPLC grade water. Linear dynamic ranges for HPLC was prepared from $2-10 \mu \mathrm{g} / \mathrm{mL}$ by the standard solutions.

Concentration ranges of about $10-30 \mu \mathrm{g} / \mathrm{mL}$ for both Chlorzoxazone and Nimesulide was prepared with distilled water and scanned at the UV range against blank solution for simultaneous equation method, derivative spectroscopy, QRatio Absorbance and Dual wavelength methods.

For the sample preparation 10 tablets were taken pulverized and weight equivalent to $10 \mathrm{mg}$ was taken and dissolved in $10 \mathrm{ml}$ of HPLC grade methanol. The solution was further diluted with HPLC grade water to get the concentration of $8 \mu \mathrm{g} / \mathrm{ml}$.

\section{RESULTS AND DISCUSSION FOR HPLC:}

The standard solutions of both Chlorzoxazone and Nimesulide were scanned in the UV range of 200-400 nm against the blank solution and the wavelength of $295 \mathrm{~nm}$ was found to show appreciable absorbance for both the drugs.

Many trails were performed by the change of different columns, mobile phase and their ratios out of which a suitable method was developed by the C18 column, mobile phase of Methanol: $0.1 \%$ Ortho-phosphoric acid (75:25), with the flow rate of about $1 \mathrm{ml} / \mathrm{min}$ and the run time of $7 \mathrm{~min}$. Peaks were eluted and showed better resolution, theoretical plate count and asymmetry was found at 4.69 and $5.45 \mathrm{~min}$ respectively for Chlorzoxazone and Nimesulide. The chromatogram of both the drugs was shown in the Figure 3.

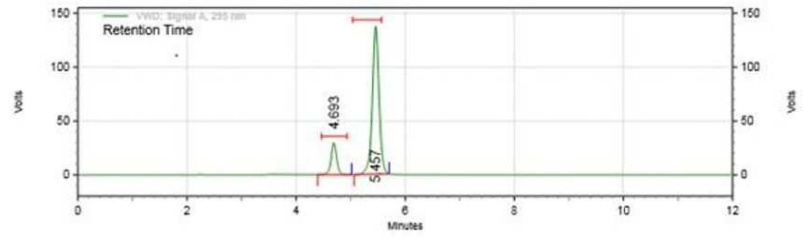

Figure 3: Chromatogram of Chlorzoxazone and Nimesulide.

\section{FOR SIMULTANEOUS EQUATION METHOD:}

The standard solutions of both Chlorzoxazone and Nimesulide were scanned in the UV range and the wavelength was found to be $280 \mathrm{~nm}$ and $390 \mathrm{~nm}$ respectively. Calibration curves were plotted for both the drugs with the concentration range of $10-30 \mu \mathrm{g} / \mathrm{mL}$. Absorption spectrum for both the drugs was shown in the Figure 4 and Figure 5 respectively. The absorbance and absorptivity values at particular wavelengths were submitted in the following equation to obtain the concentration.

$$
\begin{aligned}
& C x=(\text { A2ay1-A1ay2)/(ax2ay1-ax1ay2) } \\
& C y=(A 1 a x 2-A 2 a x 1) /(\text { ax2ay1-ax1ay2) }
\end{aligned}
$$

Where,

$\mathrm{Cx}=$ concentration of $\mathrm{CZ}$

$\mathrm{Cy}=$ concentration of NIM

$\mathrm{A} 1=$ absorbance of samples at $280 \mathrm{~nm}$.

A2 = absorbance of samples at $390 \mathrm{~nm}$.

ax1 is the absorptivity of CZ at $280 \mathrm{~nm}$.

ax2 is the absorptivity of CZ at $390 \mathrm{~nm}$.

ay1 is the absorptivity of NIM at $280 \mathrm{~nm}$.

ay2 is the absorptivity of NIM at $390 \mathrm{~nm}$.

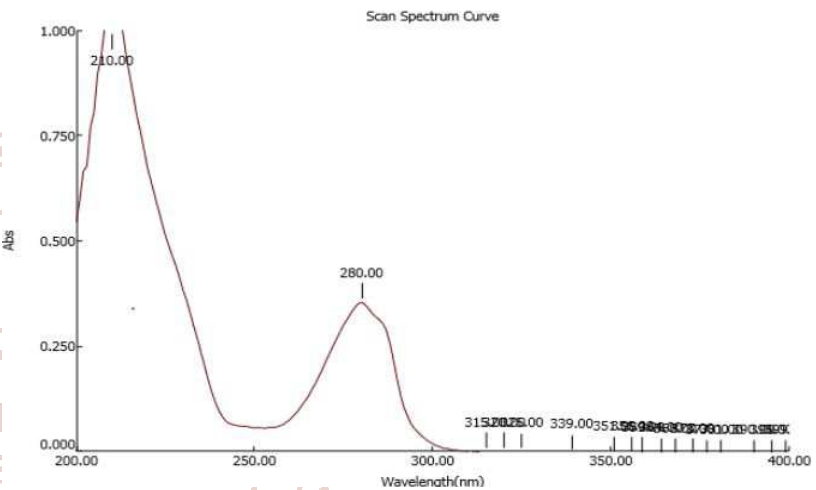

Figure 4: Spectrum of Chlorzoxazone at $280 \mathrm{~nm}$.

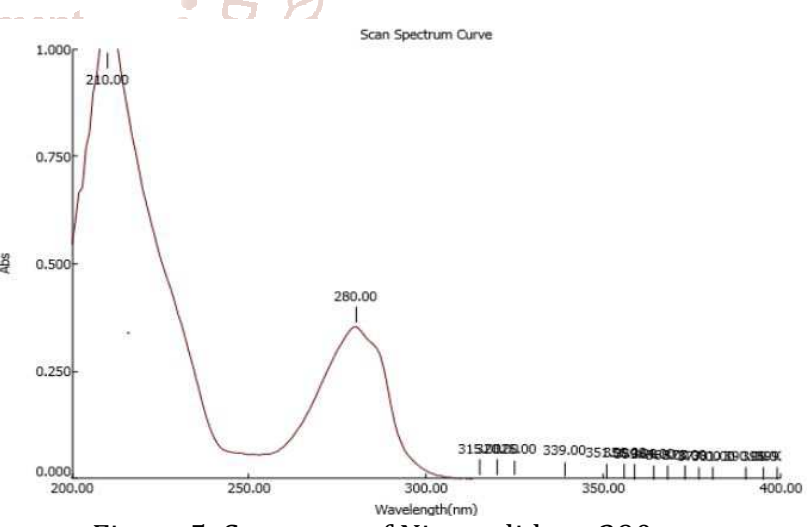

Figure 5: Spectrum of Nimesulide at $390 \mathrm{~nm}$

\section{FOR SPECTROPHOTOMETRIC FIRST DERIVATIVE ZERO- CROSSING METHOD:}

Working standard stock solutions were scanned in the UV range (215-400 $\mathrm{nm}$ ), the absorption spectra thus obtained were derivatized to first order and from the overlain spectra of both drugs wavelengths were selected.

First order derivative spectra was determined for both drugs as shown in the Figure 6-7. zero crossing point was at 244 $\mathrm{nm}$ and $388 \mathrm{~nm}$ for Chlorzoxazone and nimesulide respectively.From the overlain spectra of both the drugs wavelengths selected for quantization were $388 \mathrm{~nm}$ for CZ (Zero crossing point of NIM) and $244 \mathrm{~nm}$ for NIM (Zero crossing point of CZ). The calibration curves for CZ and NIM was plotted in the concentration range of $10-30 \mu \mathrm{g} / \mathrm{ml}$ at wavelengths of $244 \mathrm{~nm}$ and $388 \mathrm{~nm}$ respectively. 


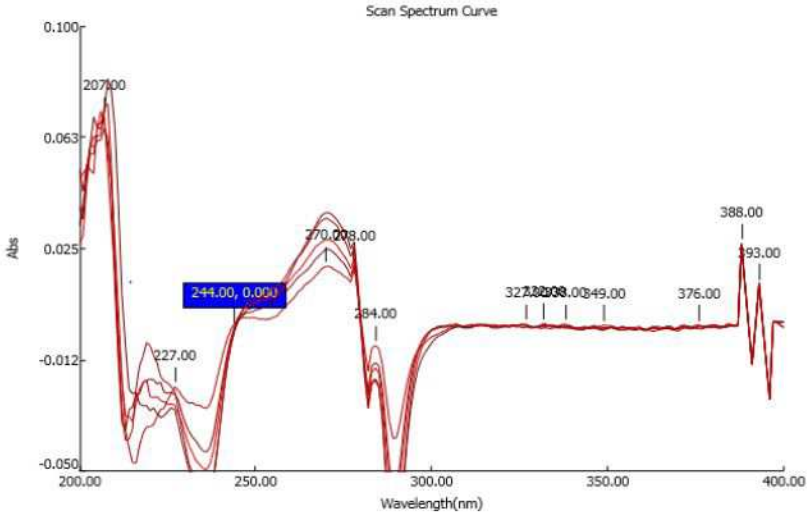

Figure 6: first order derivative overlain spectra of Chlorzoxazone at $244 \mathrm{~nm}$.

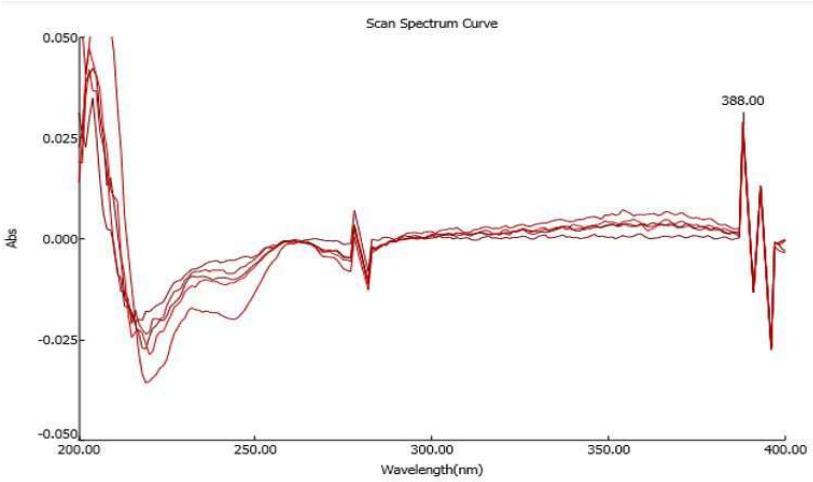

Figure 7: first order derivative overlain spectra of Nimesulide at $388 \mathrm{~nm}$.

FOR Q-RATIO ABSORBANCE METHOD:

From the overlain spectrum of both the drugs isoabsorptive point for the drugs was found to be $268 \mathrm{~nm}$.The concentration of two drugs in the mixture was calculated by using following equations.

$\mathrm{CX}=(\mathrm{QM}-\mathrm{QY})^{*} \mathrm{~A} 1 /(\mathrm{QX}-\mathrm{QY})^{*} \mathrm{aX} 1$

$\mathrm{CY}=\mathrm{A} 1 / \mathrm{aX} 1-\mathrm{CX}$

Where A1 and A2 are absorbance's of the mixture at $280 \mathrm{~nm}$ and 390nm respectively; aX1 and aY1 are absorptivites of CZ and NIM respectively at $280 \mathrm{~nm}$ and aX2 and aY2 are absorptivites of CZ and NIM respectively at 390nm.

$\mathrm{QM}=\mathrm{A} 2 / \mathrm{A} 1, \mathrm{QX}=\mathrm{AX} 2 / \mathrm{AX} 1$ and $\mathrm{QY}=\mathrm{AY} 2 / \mathrm{AY} 1$.

Overlain spectrum of the drugs was shown in the Figure 8.

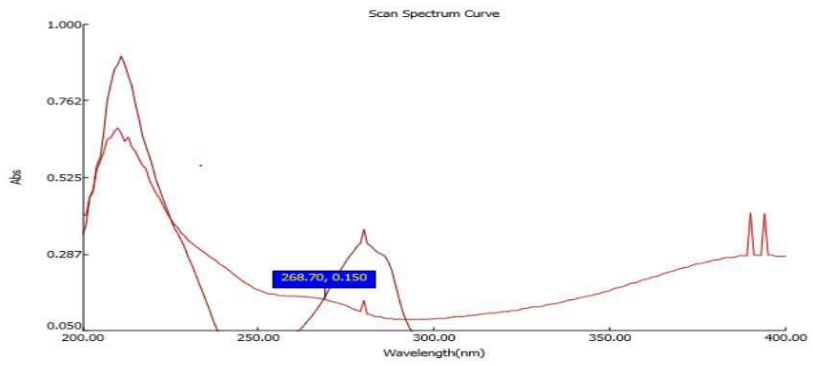

Figure 8: Overlain spectra of CZ and NIM showing IsoAbsorptive point at $268 \mathrm{~nm}$

FOR DUAL WAVELENGTH METHOD:

$10 \mu \mathrm{g} / \mathrm{ml}$ concentration of both the drugs were scanned in the UV range and from the overlain spectra of both the drugs $279 \mathrm{~nm}$ and $289 \mathrm{~nm}$ was selected as $\lambda 1$ and $\lambda 2$ for estimation of CZ where NIM shows the same absorbance at this wavelength. Similarly, wavelengths $386 \mathrm{~nm}$ and $398 \mathrm{~nm}$ were selected as $\lambda 1$ and $\lambda 2$ for estimation

of NIM where CZ shows the same absorbance at these wavelengths. Overlain spectrum for dual wavelength method was shown in the Figure 9.

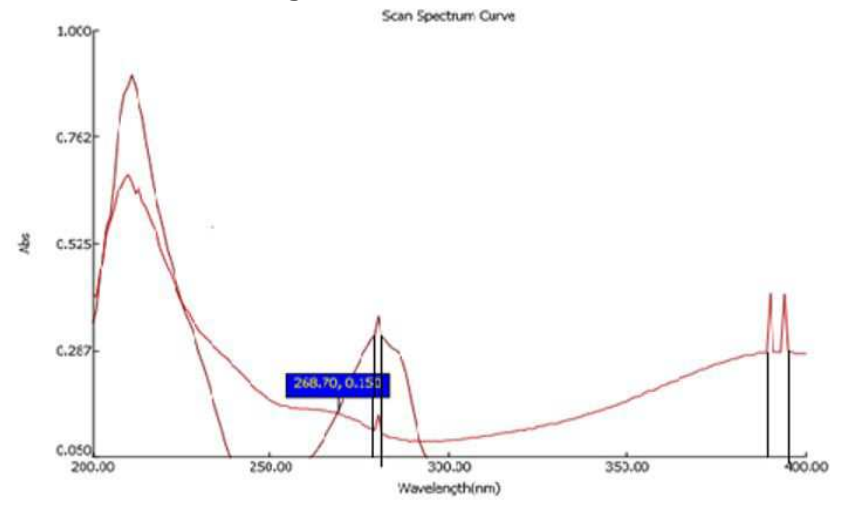

Figure 9: Spectrum of Dual wavelength method

\section{METHOD VALIDATION:}

\section{LINEARITY:}

The Linearity of analytical method is its ability to obtain test results, which are directly proportional to the concentration of analyte in the test sample. It is evaluated by analyzing a series of different concentrations ranging between 2-10 $\mu \mathrm{g} / \mathrm{ml}$ and $10-30 \mu \mathrm{g} / \mathrm{ml}$ of both CZ and NIM for HPLC and other methods respectively. Calibration graphs were plotted and linear relationship was established.

\section{PRECISION:}

The precision of the analytical method was studied by analysis of multiple sampling of homogenous sample, expressed as \%RSD. Method Reproducibility was demonstrated by repeatability and intermediate precision measurements. The repeatability (within in the day) and intermediate precision (for 3 days) was carried for each compound. The obtained results within and between days trails are in acceptable range indicating good precision of the proposed method.

\section{ACCURACY:}

The accuracy of an analytical method is the closeness of test results obtained by that method compared with the true values. To confirm the accuracy of the proposed method, recovery experiments were carried out by standard addition technique. The accuracy of the method was carried out by adding by known amounts of each drug corresponding to three concentration levels, 80,100 and $120 \%$ of the label claim along with the excipients in triplicate. The samples were given the same treatment as described in sample preparation. The percentage recoveries of CZ and NIM at each level and each replicate were determined. The mean of percentage recoveries $(n=3)$ and the relative standard deviation was calculated. It was confirmed from results that the method is highly accurate.

LIMIT OF DETECTION AND LIMIT OF QUANTIFICATION: Calibration curve was repeated for 5 times and the standard deviation (SD) of the intercepts was calculated for UV and Chromatogram signals obtained with known low concentrations of analytes was compared with the signals of blank samples, a signal- to- noise ratio $3: 1$ and $10: 1$ is considered for calculating LOD and LOQ respectively for HPLC. 
International Journal of Trend in Scientific Research and Development (IJTSRD) @ www.ijtsrd.com eISSN: 2456-6470

\section{ROBUSTNESS:}

The robustness of the method was determined by making slight changes in the chromatographic conditions. The robustness of the proposed HPLC method was assessed for peak resolution and symmetric factor. The parameters investigated are Apparent $\mathrm{pH}$ of the mobile phase, Mobile phase organic content, Mobile phase flow rate, Detection wave length.

\section{SYSTEM SUITABILITY:}

System precision was determined on six replicate injections of standard preparation all important characteristics including \%RSD, resolution (between CZ and NIM), tailing factor and theoretical plate number were measured.

\section{ASSAY OF TABLETS:}

Applicability of the method was tested by analyzing the commercially available formulations containing the binary mixture of $\mathrm{CZ}$ and NIM. The values of \% recovery from formulations are found to be very close to each other as well as to the label value of commercial pharmaceutical formulation.

Results for the validation parameters for all the methods are shown in Tables

Table 1:Simultaneous estimation of Chlorzoxazone and Nimesulide by HPLC

\begin{tabular}{|c|c|c|}
\hline Parameters & Chlorzoxazone & Nimesulide \\
\hline Linearity & $2-10 \mu \mathrm{g} / \mathrm{mL}$ & $2-10 \mu \mathrm{g} / \mathrm{mL}$ \\
\hline Equation $\mathrm{Y}=\mathrm{mx}$ & $\mathrm{Y}=1 \mathrm{E}+06 \mathrm{x}$ & $\mathrm{Y}=229436 \mathrm{x}$ \\
\hline Correlation coefficient & 0.9914 & 0.9948 \\
\hline $\mathrm{LOD}(\mu \mathrm{g} / \mathrm{mL})$ & 0.633 & 0.304 \\
\hline LOQ $(\mu \mathrm{g} / \mathrm{mL})$ & 1.90 & 0.912 \\
\hline Precision Intraday & 0.346 & $1.66 \mathrm{SN}$ \\
\hline Precision Interday & 0.403 & 1.93 \\
\hline Theoretical plates & 9880 & 10773 \\
\hline Asymmetry & 0.99 & 1.02 \\
\hline Retention time & 5.467 & 4.720 \\
\hline \% Recovery & 100.93 & 102.19 \\
\hline $\begin{array}{c}\text { Amount found in } \\
\text { formulation(mg) }\end{array}$ & 249.5 & 102.09 \\
\hline
\end{tabular}

Table 2: Simultaneous estimation of Chlorzoxazone and Nimesulide using simultaneous equation method

\begin{tabular}{|c|c|c|}
\hline Parameters & $\begin{array}{c}\text { Chlorzoxazone } \\
(280 \mathrm{~nm})\end{array}$ & $\begin{array}{c}\text { Nimesulide } \\
(390 \mathrm{~nm})\end{array}$ \\
\hline Linearity & $10-30 \mu \mathrm{g} / \mathrm{mL}$ & $10-30 \mu \mathrm{g} / \mathrm{mL}$ \\
\hline Equation $(\mathrm{y}=\mathrm{mx})$ & $\mathrm{y}=0.025 \mathrm{x}$ & $\mathrm{y}=0.024 \mathrm{x}$ \\
\hline Correlation coefficient & 0.996 & 0.998 \\
\hline LOD $(\mu \mathrm{g} / \mathrm{mL})$ & 3.33 & 3.57 \\
\hline LOQ $(\mu \mathrm{g} / \mathrm{mL})$ & 10 & 10.71 \\
\hline Precision Intraday & 0.561 & 0.389 \\
\hline Precision Interday & 0.524 & 0.457 \\
\hline$\%$ Recovery & 99.7 & 100.01 \\
\hline $\begin{array}{c}\text { Amount found in } \\
\text { formulation(mg) }\end{array}$ & 248.89 & 99.23 \\
\hline
\end{tabular}

Table 3: Spectrophotometric first derivative Zerocrossing method for simultaneous estimation of Chlorzoxazone and Nimesulide

\begin{tabular}{|c|c|c|}
\hline Parameters & $\begin{array}{c}\text { Chlorzoxazone } \\
(244 \mathrm{~nm})\end{array}$ & $\begin{array}{c}\text { Nimesulide } \\
(388 \mathrm{~nm})\end{array}$ \\
\hline Linearity & $10-30 \mu \mathrm{g} / \mathrm{mL}$ & $10-30 \mu \mathrm{g} / \mathrm{mL}$ \\
\hline Equation $(\mathrm{y}=\mathrm{mx})$ & $\mathrm{y}=0.026 \mathrm{x}$ & $\mathrm{y}=0.0207 \mathrm{x}$ \\
\hline Correlation coefficient & 0.993 & 0.9913 \\
\hline LOD $(\mu \mathrm{g} / \mathrm{mL})$ & 3.95 & 3.66 \\
\hline LOQ $(\mu \mathrm{g} / \mathrm{mL})$ & 10.94 & 9.98 \\
\hline Precision Intraday & 0.4315 & 0.441 \\
\hline Precision Interday & 0.430 & 0.853 \\
\hline$\%$ Recovery & 99.97 & 99.78 \\
\hline $\begin{array}{c}\text { Amount found in } \\
\text { formulation(m) }\end{array}$ & 250.14 & 99.89 \\
\hline
\end{tabular}

Table 4: Q-Absorbance Ratio method for the simultaneous estimation of Chlorzoxazone and Nimesulide

\begin{tabular}{|c|c|c|}
\hline Parameters & $\begin{array}{c}\text { Chlorzoxazone } \\
(268 \mathrm{~nm})\end{array}$ & $\begin{array}{c}\text { Nimesulide } \\
(268 \mathrm{~nm})\end{array}$ \\
\hline Linearity & $10-30 \mu \mathrm{g} / \mathrm{mL}$ & $10-30 \mu \mathrm{g} / \mathrm{mL}$ \\
\hline Equation $(\mathrm{y}=\mathrm{mx})$ & $\mathrm{y}=0.0298 \mathrm{x}$ & $\mathrm{y}=0.0029 \mathrm{x}$ \\
\hline Correlation coefficient & 0.992 & 0.997 \\
\hline LOD $(\mu \mathrm{g} / \mathrm{mL})$ & 3.75 & 3.66 \\
\hline LOQ $(\mu \mathrm{g} / \mathrm{mL})$ & 10.25 & 9.98 \\
\hline Precision Intraday & 0.361 & 1.67 \\
\hline Sci Precision Interday & 0.540 & 1.745 \\
\hline h anc\% Recovery & 101.37 & 99.48 \\
\hline $\begin{array}{c}\text { me Amount found in } \\
\text { formulation }(\mathrm{mg})\end{array}$ & 250.15 & 99.85 \\
\hline
\end{tabular}

Table 5: Dual wavelength method for simultaneous estimation of Chlorzoxazone and Nimesulide

\begin{tabular}{|c|c|c|}
\hline Parameters & Chlorzoxazone & Nimesulide \\
\hline Equation $(\mathrm{y}=\mathrm{mx})$ & $\mathrm{y}=0.0003 \mathrm{x}$ & $\mathrm{y}=0.0028 \mathrm{x}$ \\
\hline Correlation coefficient & 0.9924 & 0.997 \\
\hline $\mathrm{LOD}(\mu \mathrm{g} / \mathrm{mL})$ & 3.41 & 3.63 \\
\hline LOQ $(\mu \mathrm{g} / \mathrm{mL})$ & 10.23 & 9.89 \\
\hline Precision Intraday & 1.96 & 1.696 \\
\hline Precision Interday & 1.258 & 1.66 \\
\hline \% Recovery & 100.13 & 99.96 \\
\hline $\begin{array}{c}\text { Amount found in } \\
\text { formulation }(\mathrm{mg})\end{array}$ & 248.98 & 99.63 \\
\hline
\end{tabular}

\section{CONCLUSION}

All the proposed spectrophotometric and chromatographic methods were found to be simple, sensitive, accurate and precise for the determination of Chlorzoxazone and Nimesulide in the pharmaceutical dosage form. The methods utilizes easily available and less economical solvent for analysis of Chlorzoxazone and Nimesulide hence the methods were economical for the estimation of Chlorzoxazone and Nimesulide in synthetic mixture. 


\section{REFERENCES}

[1] Snehal J. More, Suparna S. Tandulwadkar, Ajinkya R.Nikam, AtulS.Rathore, L.Sathiyanarayanan, and Kakasaheb R.Mahadik (2012). Application of HPLC for the Simultaneous Determination of Paracetamol, Chlorzoxazone, and Nimesulide in Pharmaceutical Dosage Form. ISRN Chromatography Volume 2012, Article ID: 252895, P1-8.

[2] S. Ravisankar, M. Vasudevan, M. Gandhimathi, B.Suresh. (1998). Reversed-phase HPLC method for the estimation of acetaminophen, ibuprofen and chlorzoxazone in formulations. Elsevier, 46(6), P 1577 1581.

[3] Vinod Maheshwari, Jaydeep Sangani, Naimish Kariya, Payal Maheshwari, Jenisha Roka. Development And Validation of Rp-Hplc Method For Simultaneous Estimation Of Diclofenac Sodium And Chlorzoxazone In Their Combined Tablet Dosage Form. Inventi: ppaqa/1049/13.

[4] Jigar Patel, Pinak Patel (2014). Rp-Hplc Method Development And Validation For The Estimation of Diclofenac Sodium, Tramadol Hydrochloride And Chlorzoxazone From Their Combined Tablet Dosage Form. International Journal of Pharmacy and Pharmaceutical Sciences. 6(7), P632-637.
[5] Shaikh K, Devkhile A (2008). Simultaneous determination of aceclofenac, paracetamol, and chlorzoxazone by RP-HPLC in pharmaceutical dosage form. J Chromatogr Sci. 46(7), P649-52.

[6] Nitin D. Rawool*, A. Venkatchalam (2013). Development and validation of a rapid HPLC method for the simultaneous estimation of nimesulide and tizanidine hydrochloride in pharmaceutical tablet dosage form. ACAIJ, 12(11), P408-414.

[7] British Pharmacopoeia 2007, Volume I \& II, Accessed soft copy.

[8] Indian Pharmacopoeia 2007, Volume II,Published by the controller of Publication, Ministry of Health and Family welfare, New Delhi 681.

[9] Yousry M. Issa, Sayed I.M. Zayed, Ibrahim H.I. Habib (2010). Simultaneous determination of ibuprofen and paracetamol using derivatives of the ratio spectra method. Arabian Journal of Chemistry. 4, P259-263.

[10] Dr. A. Rajasekaran (2010). Hand book of ultra-visible \& infrared spectroscopy. Tamil Nadu: Rupi publication. P76-83.

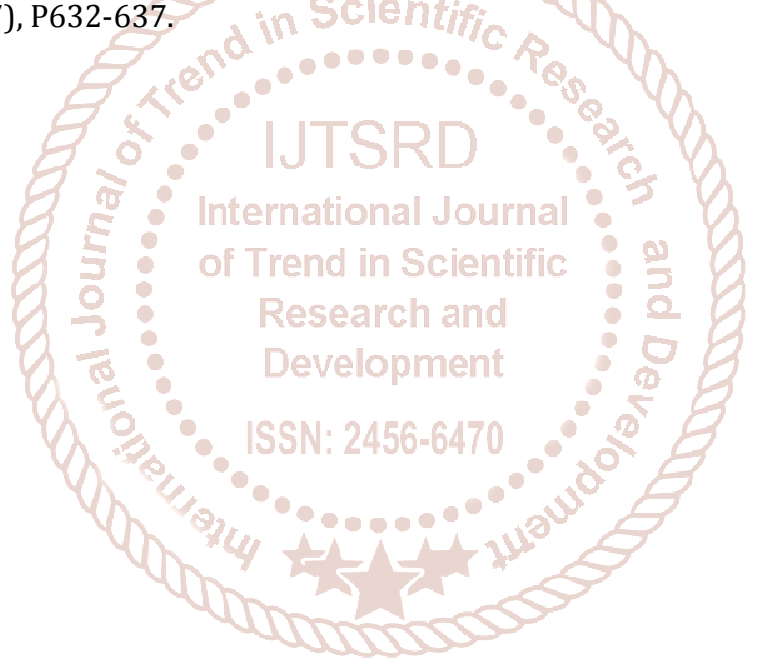

